\title{
Translators' Use of Digital Resources during Translation
}

\begin{abstract}
This paper presents the findings from a study on translators' use of digital resources during the translation process. Eye tracking data and screen recording data from 18 professional translators are analysed in order to 1) examine how much time translators spend on digital resource consultation compared with translation drafting and translation revision, 2) examine how eye movements differ between translation drafting, revision and digital resource consultation and 3 ) investigate what types of digital resources are used by translators. The findings demonstrate that digital resource consultation constitutes a considerable amount of the translation process. The findings also show longer fixations and larger pupils during resource consultation, indicating heavier cognitive load, and finally the study identifies considerable variation in the use of resources between translators.
\end{abstract}

\section{Keywords}

translation aids, digital resources, dictionaries, allocation of resources, translation, eye tracking

\section{Introduction and background}

Translators often rely on external resources to solve translation problems. Print dictionaries, parallel texts and digital resources such as bi- and monolingual dictionaries, internet-based encyclopaedias and internet search engines are indispensable translation tools that translators use to solve a multitude of translation problems. In translation process research (TPR), most studies focus entirely on translators' interaction with the source and target texts, and the translators' use of digital resources has attracted little attention. This focus is a logical first step since translation, primarily, consists of source text comprehension and target text production. However, translation can rarely be carried out successfully without the use of some kind of translational aid, and in order to describe the translation process in more detail it is necessary to examine how digital resources are used and integrated into the translation process. Hvelplund/Dragsted (2017) is one example of research into the use of digital resources during the translation process. They focus specifically on language for special purposes (LSP) translators' and literary translators' use of different search strategies in the translation process and find that the former apply more advanced strategies than the latter; but other than the findings from their study, little is known of how digital resources such as internet dictionaries, websites and other digital tools are integrated into the translation process. For instance, it is not known which types of translation tools are used, if there are behaviours that are specific to certain kinds of problems, how professionals use digital resources differently than novices, let alone how much time is actually spent on resource consultation during the translation process. While studies in the field of lexicography have examined the use of internet dictionaries using eye tracking in isolation from actual translation (e.g. Simonsen 2009, 2011), there seems to be a gap in the literature on translators' integration of digital resources in the translation process. Exploring the role and use of digital resources may be helpful to identify behaviours that are more

\footnotetext{
* Kristian Tangsgaard Hvelplund

Department of English, Germanic and Romance Studies

University of Copenhagen

kristian.hvelplund@hum.ku.dk
} 
desirable than others, and the findings may be instrumental to the development of recommendations and guidelines for the use of digital resources.

\section{Background and research aims}

This article presents and discusses the findings of an empirical investigation of the use of digital resources in the translation process. The research aims of the study are threefold: 1) identify the importance of digital resources as indicated by time spent on various translation-related activities, 2) identify to what extent translating and digital resource consultation are characterised by different reading patterns and different cognitive load and 3) identify which online digital resources are used. Sections 2.1, 2.2. and 2.3. below each consider one of those different aspects.

In the context of this paper, digital resources are defined as those external digital aids that are not integrated into the text processing interface, internet-based as well as non-internet based, which the translator may access from the computer in order to solve translation problems. As such, digital resources are understood to be different from software such as SDL Trados, MemoQ and Memsource, which are translation environment tools that are integrated into the text processing interface.

\subsection{Attention distribution}

Attention distribution, sometimes also called (cognitive) resource distribution, ${ }^{1}$ is an indicator of the amount of temporal effort allocated to the various activities that make up the translation process. Effort in this context is measured by the amount of time that is spent on a given activity. Depending on the research scope, different activities may be identified. Some studies have considered differences in temporal effort between source text processing and target text processing, while others have considered differences between orientation, drafting and revision. For instance, with respect to orientation, drafting and revision, Jakobsen (2002: 92) observed that the amount of time allocated to the orientation phase amounted to just 3 per cent of the total production time while the drafting phase made up 77 per cent of the total. Around 20 per cent of the production time was allocated to the revision phase. As regards differences between source text and target text, Hvelplund (2011: 128) found that translators spent roughly three times the amount of time working with the target text (TT) compared with the source text (ST). As regards temporal effort allocated to dictionary lookups, Google searches, Wikipedia consultation etc., it is not yet known how much (or little) time is allocated to these tasks. One central aim of this study is to examine how much time is actually allocated to digital resource consultation compared with translation drafting and translation revision. These findings will provide a first indication of the importance of external resources in the translation process.

\subsection{Reading behaviour and cognitive load}

Reading in translation has been the object of research in a number of TPR studies. Considered to be the first eye tracking study to examine translation reading, Jakobsen/Jensen's (2008) study compares reading during translation with other kinds of translation reading, including reading for comprehension, reading in preparation for translating and reading while speaking a translation (i.e. sight translation). The study shows that the purpose of reading has a clear effect on fixation count and fixation duration and that reading during translation is characterised by more and longer fixations. Taking a more granular look at the different kinds of reading that may take place during the translation process, Hvelplund (2017) describes four different kinds of reading: source text reading without concurrent typing, source text reading while typing the target text, target text reading without concurrent typing, and target text reading while typing the target text. Fixation

1 The term attention distribution has been chosen instead of resource distribution to avoid terminological confusion as the term resources is already used in relation to translation aid resources. 
duration as well as pupil sizes vary considerably and significantly between all these kinds of reading and the results show that many different kinds of reading can occur during translation.

While measures of fixations have been popular to describe overall reading characteristics of translation reading, some studies have also examined differences in pupil sizes in order to examine the workload that is placed on the translator's cognitive system while translating. Hvelplund (2011) and (2016) are examples of such studies and they demonstrate that expertise (professional vs novice) as well as reading type (source text reading vs target text reading) have a clear effect on pupil size: professionals seem to automate translation behaviour more than novices and target text reading involves more effort than source text reading.

There has been no systematic investigation so far into reading behaviour and cognitive load during digital resource consultation. While it is likely that reading and cognitive load differ during this activity from 'translation proper', this assumption still needs to be confirmed and described empirically. This study will examine eye movement behaviour during digital resource consultation and investigate if and in what respects eye movement behaviour is different during translation drafting and translation revision.

\subsection{Digital resources}

As mentioned above, translators' use of digital resources such as dictionaries, websites and search engines has not yet been described systematically and empirically in Translation Studies. This is surprising since the use of such resources often make up a considerable part of the translation process. One study to observe and discuss the translation process in relation to digital resource consultation is Hvelplund/Dragsted (2017), who note that text type has an effect on the number of resource consultations and the duration of those consultation events. Figures from their study indicate that translation of LSP text involves three times as many resource consultations as the translation of literary text. On average, LSP translation involves one resource consultation per 34 words and literary translation involves one resource consultation per 108 words. This difference may not be surprising since low-frequency terms occur far more often in LSP text than in literary text. What is interesting, however, is that the duration of each resource consultation event does not vary much: 8.9 seconds for literary translation and 7.5 seconds for LSP translation. Besides this study, process research into the type, kind and nature of digital resources used by translators is limited and a research gap remains to be bridged.

A central aim of this study is to explore which digital resources are used to solve specific translation problems. This investigation will make it possible to outline and quantify which resources are used and if there are resource consultation behaviours that are more desirable than others. In addition, the investigation will explore if and to what extent translators make use of different resource consultation strategies or if there are prototypical strategies shared by (many) translators.

Based on the outlines presented in the sections above, the investigation into translators' use of digital resources in the translation process will take its point of departure in three specific research questions:

R1: How much time is spent on digital resource consultation compared with translation drafting and translation revision?

R2: How are eye movements different during digital resource consultation than during translation drafting and revision?

\section{R3: What types of digital resources are used in translation?}

\section{Research design}

The analyses of the study are based on translation process data, which were originally collected for Hvelplund/Dragsted's (2017) study on differences between literary translators and LSP trans- 
lators. During this study, the participants had access to online digital resources. The translation process data consist of eye movement data and screen recording data. R1 is investigated by examining the amount of time allocated to the drafting and revision phases as well as to digital resource consultation. R2 is examined by analysing differences in fixation duration and pupil size. R3 is explored by examining the frequency of usage for different types of digital resources.

\subsection{Participants, texts and procedure}

A total of 23 professional translators took part in a series of translation recording sessions. The translators had at least four years of translating experience (range $=4-51$ years, experience mean $=15$ years). The recordings of five translators had to be discarded (Ibid.) either due to data quality issues or data incompleteness. This study's analyses are based on the data from the remaining 18 translators.

Four English-language texts (Text 1 - Text 4) were used in Hvelplund/Dragsted's (2017) study (see Appendix 1). Two texts can be described as fiction: Text 1, an excerpt from John Le Carré's novel Single \& Single, and Text 2, an extract from the 2001 novel All families are psychotic by Douglas Coupland. Two texts may be considered LSP texts: Text 3, an annual report from British American Tobacco Company, and Text 4, an extract from a technical report.

The translators were asked to translate the texts into Danish and to produce translations that could be sent off to a hypothetical client. All translators had unrestricted access to the internet as well as to online Danish-English-Danish bilingual dictionaries such as Gyldendals Røde Ordbøger and Ordbogen.com.

\subsection{Recording equipment and software}

Translation process data were collected in a series of translation recording sessions that were carried out from September to December 2014 at eye tracking laboratories at the Copenhagen Business School (CBS), which hosts a Tobii X120 eye tracker, and at the University of Copenhagen, which also hosts a Tobii X120 eye tracker. In order to secure good and comparable eye tracking data, the recording sessions were carried out in rooms with no natural light. Tobii Studio was used to collect eye movement data and Translog II (version 0.1.0.189) (Jakobsen/Schou 1999, Carl 2012) was used to present the source text and the input window for the target text. The keylogging data collected with Translog II will not be analysed in this article.

\subsection{Statistical analysis and variables}

Descriptive and inferential statistical analysis are used to examine the study's eye movement data and screen recording data. Descriptive statistics is used to comment on research questions R1-R3 while inferential statistics is used to examine more closely whether there are significant differences between digital resource consultation and translation drafting and revision as regards attention distribution (R1) and fixation duration and pupil size (R2).

The study's analyses rest on four sets of data. The attention distribution data set consists of 216 items and is used in the analyses of R1. For each translator, it contains information about translator number (P1 ... P18), text (Text 1, Text 2, Text 3, Text 4), activity type (digital resource consultation, drafting and revision), duration of an activity (in seconds) and text type (literary, LSP). The second data and third data sets are the fixation duration and pupil size data sets (used to answer R2). They consist of 120,259 items and 110,472 items, respectively. In addition to information about either fixation duration or pupil size, each item in the data sets contains information about translator number, text, activity type and text type. The fourth data set digital resources consists of 682 items and is used to analyse R3. For each digital resource consultation, it contains information about translator number, text, digital resource task (e.g. bi-/mono-lingual dictionary lookup, Google search, Google Images search etc.), activity duration (in seconds) and text type. 
In order to analyse the eye movement data inferentially, linear mixed-effects regression (LMER) models (e.g. Baayen 2009, Balling 2008, Balling/Hvelplund 2015) were fitted in the statistical environment R: one for the attention distribution analysis, which uses the attention distribution data set, one for the fixation duration analysis, which uses the fixation duration data set and one for the pupil size analysis, which uses the pupil size data set. The fixation duration data were heavily positively skewed and logarithmic transformation was carried out to achieve a normal distribution. No logarithmic transformation was carried out for the other data sets. To counteract the issue of multiple comparisons, Bonferroni correction (Baayen 2009: 106) was used. The adjusted p-level was $0.05 / 6=0.008$.

\section{Results and discussion}

This section presents and discusses the results of the study's analyses with a point of departure in the research questions outlined in section 2. The results of the analysis of attention distribution are presented and discussed in section 4.1., reading behaviour and cognitive load in section 4.2., and types and usage of digital resources in section 4.3.

\subsection{Attention distribution}

Attention distribution, as indicated by the total amount of time allocated to translation drafting, translation revision and digital resource consultation, is useful to examine the relative temporal weight of these activities in the overall translation process. This section concerns research question R1:

How much time is spent on digital resource consultation compared with translation drafting and translation revision?

Figure 1 below provides some indication of the amount of time spent by translators on these three activities.

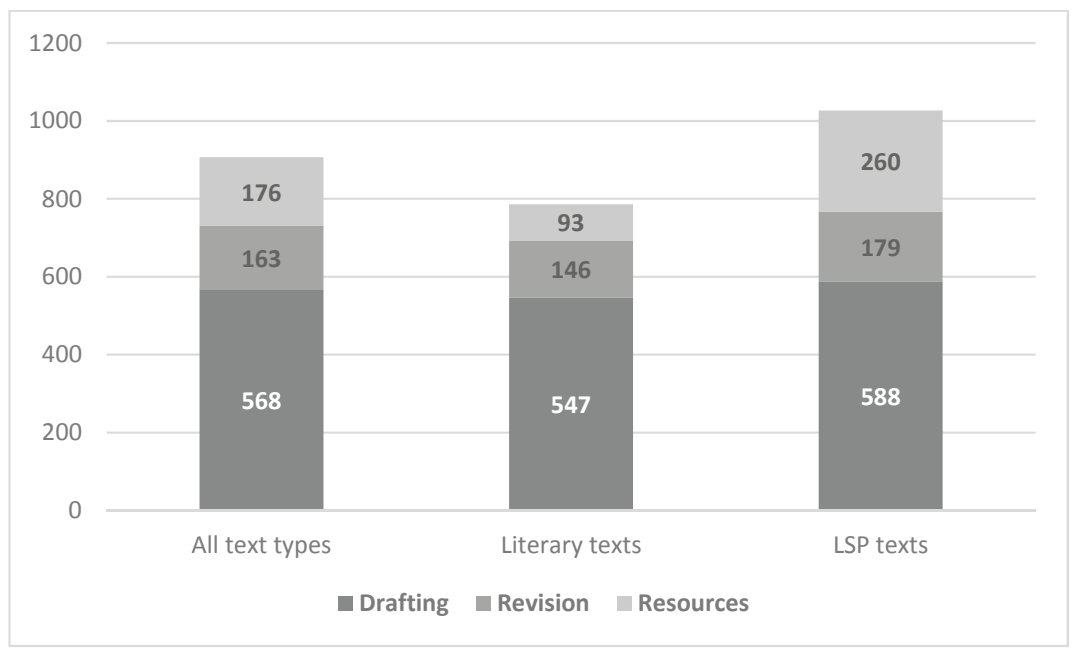

Figure 1. Temporal distribution (means) in seconds. Drafting (dark grey), revision (grey), search/digital resource consultation (light grey)

Overall, digital resource consultation accounts for roughly 19.4 per cent (176 seconds) of the overall translation task time with 62.6 per cent (568 seconds) allocated to translation drafting and 18 per cent (163 seconds) allocated to translation revision. The LMER analysis shows that the overall effect of activity on activity duration is significant $(\mathrm{p}<0.0001)$. However, none of the relevant pairwise comparisons that concerned digital resource allocation reached significance, possibly due to the scarcity of the data set, which consists of only 216 items. A larger data set may be 
able to support the indication by the descriptive figures. Nevertheless, the figures indicate that a considerable amount of the translation process - nearly one fifth - is not directly related to source text or target text reading. As discussed in section 2, the role and use of digital and non-digital resources has rarely been a central object of study in process research, let alone a peripheral one. However, the findings above suggest that the role and use of resources should be given more attention since digital resources constitute such a large part of the translators' work. By including translators' use of resources in the analysis, studies will in turn achieve a higher level of 'completeness' in the description of the translation process.

As indicated by the means, text type seems to have an effect on the amount of time that is spent on digital resources: for literary texts, time allocated to digital resource consultation is 11.8 per cent (93 seconds) of the total translation task time while the corresponding percentage for the LSP texts is considerably higher, namely 25.3 (260 seconds). This effect of text type on resource allocation might not be very surprising, since different texts pose different kinds of problems; the translation of LSP texts, as a case in point, implies more frequent dictionary lookups to solve a higher number of terminological problems. However, the outline of overall time distribution above does not indicate how translators spend time during resource consultation, and the natural question then is what are the translators doing while not drafting or revising their translations. Is time spent looking in dictionaries, searching Google, browsing websites or performing some other task? We will return to this point regarding the nature of resource consultations in section 4.3., but first we investigate how reading behaviour and cognitive load differ between 'translation proper' and resource consultation.

\subsection{Eye movements}

This section investigates fixation durations and pupil sizes during digital resources consultation and examines if and to what extent they are different from fixation durations and pupil sizes during translation drafting and during revision. The analyses take as point of departure research question R2:

\section{How are eye movements different during digital resource consultation than during translation drafting and revision?}

Fixation duration is taken as an indicator of effort involved in a given activity (following Just/ Carpenter's (1980) eye-mind and immediacy assumptions) as longer fixations indicate more effortful processing and shorter fixations indicate the opposite. Pupil size is taken as an indicator of the cognitive load placed on the cognitive system during a given activity (cf. Hess/Polt 1964) as smaller pupils indicate less cognitive load and larger pupils indicate the opposite.

\subsubsection{Fixation duration}

The means presented in Figure 2 below show that fixations are generally longer when consulting digital resources than during translation drafting and translation revision. Fixations during resource consultation are between 9 and 54 per cent longer than during drafting and revision, and thus there is strong indication that digital resource consultation involves increased cognitive processing. 


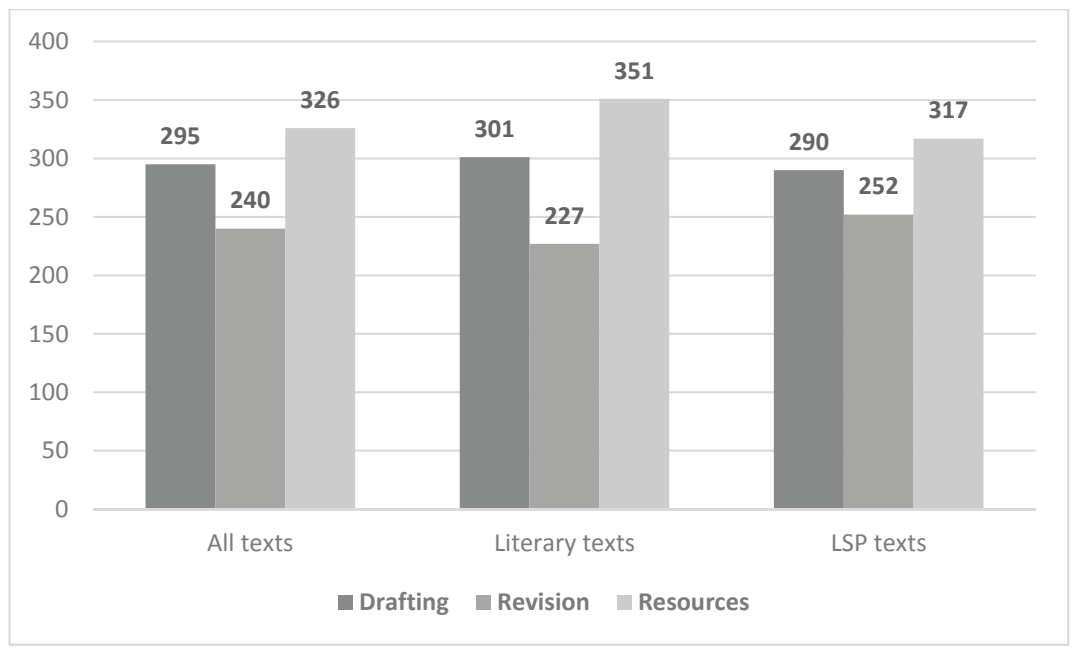

Figure 2. Fixation duration (means) in milliseconds. Drafting (dark grey), revision (grey), search/digital resource consultation (light grey)

In order to examine if the indication by the descriptive means can be confirmed, an LMER analysis was carried out (see section 3.3). This analysis provides overall confirmation, as all relevant comparisons are significant, cf. Table 1 below. In all comparisons, except one (Translation drafting $\leftrightarrow$ resource consultation, LSP texts), fixations were significantly longer, thus confirming that resource consultation is associated with heavier processing than translation drafting and revision.

\begin{tabular}{|c|c|c|c|c|}
\hline Text & Activities & Mean duration ms & $p$-value ${ }^{2}$ & $t$-value \\
\hline \multirow[t]{2}{*}{ All texts } & Drafting $\leftrightarrow$ Digital resources & $295 \mathrm{~ms} \leftrightarrow 326 \mathrm{~ms}$ & $<0.0001^{*}$ & $=5.646$ \\
\hline & Revision $\leftrightarrow$ Digital resources & $240 \mathrm{~ms} \leftrightarrow 326 \mathrm{~ms}$ & $<0.0001 *$ & $=17.537$ \\
\hline \multirow[t]{2}{*}{ Literary texts } & Drafting $\leftrightarrow$ Digital resources & $301 \mathrm{~ms} \leftrightarrow 351 \mathrm{~ms}$ & $<0.0001 *$ & $=7.521$ \\
\hline & Revision $\leftrightarrow$ Digital resources & $227 \mathrm{~ms} \leftrightarrow 351 \mathrm{~ms}$ & $<0.0001^{*}$ & $=15.935$ \\
\hline \multirow[t]{2}{*}{ LSP texts } & Drafting $\leftrightarrow$ Digital resources & $290 \mathrm{~ms} \leftrightarrow 317 \mathrm{~ms}$ & $=0.02371$ & $=2.262$ \\
\hline & Revision $\leftrightarrow$ Digital resources & $252 \mathrm{~ms} \leftrightarrow 317 \mathrm{~ms}$ & $<0.0001 *$ & $=10.172$ \\
\hline
\end{tabular}

Table 1. Differences in fixation duration

A likely explanation for the longer fixations is that the activity of digital resource consultation is composed of a greater variety of underlying tasks than the activities of drafting and revising. The tasks associated with drafting and revision consist primarily of source text reading and target text reading, rereading of both texts and typing and other text production related tasks. There is a greater variety of tasks associated with resource consultation, which may include very different tasks such as looking up words in the dictionary, browsing websites, performing search engine searches, reading encyclopaedia articles, viewing images, and so on. This potential variation in tasks during digital resource consultation may thus contribute strongly to the relatively heavier processing demands. In other settings, some of these tasks have been found to be associated with longer fixations; fixations during visual search, for instance, are generally longer than reading fixations (Rayner 1998: 373) as are fixations when reading lists of search results produced by search engines (Rele/Duchowski 2005). Considering the heterogeneous nature of resource consultation during translation, it may even be speculated whether it is meaningful at all to regard reading during digital resource consultation as one kind of reading, since, potentially many dif-

2 An asterisk indicates a significant difference at the Bonferroni-corrected level (see Section 3.3). 
ferent underlying tasks are involved. Section 4.3. below will discuss this variation in tasks, but as regards different kinds of reading during resource consultation, this paper will not explore it in more detail; future studies may, however, wish to explore the complexity of reading during resource consultation.

\subsubsection{Pupil size}

Figure 3 below presents pupil size means for drafting, revision and digital resource consultation for literary texts and LSP texts as well for both text types. Variation in pupil size is taken as an indicator of variation in the cognitive load placed on the translators' cognitive systems. The means show that pupils are consistently larger (between 0.4 and 2.2 per cent larger) during digital resource consulting than during translation drafting and translation revision. Although the difference does not seem to be as profound compared with the results of the fixation analysis above, the difference is systematic and reflects the pattern identified in the fixation duration analysis.

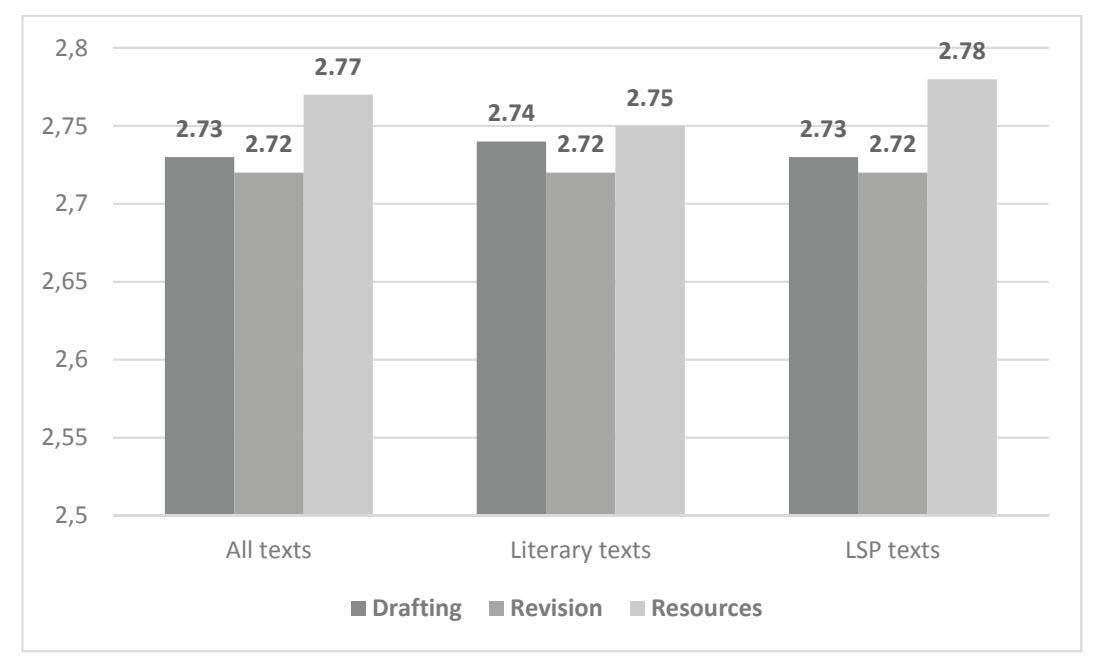

Figure 3. Pupil size (means) in millimetres. Drafting (dark grey), revision (grey), search/digital resource consultation (light grey)

In parallel with the fixation analysis above, an LMER analysis was carried out in order to examine if the indication by the descriptive means can be confirmed inferentially. In the analysis of variation in pupil sizes, all relevant comparisons turn out to be significant, cf. Table 2 below. The analysis thus confirms that cognitive load is higher during resource consultation than during translation drafting and revision.

\begin{tabular}{l|lllc}
\hline Text & Activities & Mean size $\mathbf{m m}$ & $\boldsymbol{p}_{\text {-value }}^{\mathbf{3}}$ & $\boldsymbol{t}_{\text {-value }}$ \\
\hline All texts & Drafting $\leftrightarrow$ Digital resources & $2.73 \mathrm{~mm} \leftrightarrow 2.77 \mathrm{~mm}$ & $<0.0001^{*}$ & $=14.39$ \\
& Revision $\leftrightarrow$ Digital resources & $2.72 \mathrm{~mm} \leftrightarrow 2.77 \mathrm{~mm}$ & $<0.0001^{*}$ & $=35.92$ \\
\hline Literary texts & Drafting $\leftrightarrow$ Digital resources & $2.74 \mathrm{~mm} \leftrightarrow 2.75 \mathrm{~mm}$ & $<0.0001^{*}$ & $=5.049$ \\
& Revision $\leftrightarrow$ Digital resources & $2.72 \mathrm{~mm} \leftrightarrow 2.75 \mathrm{~mm}$ & $<0.0001^{*}$ & $=25.483$ \\
\hline LSP texts & Drafting $\leftrightarrow$ Digital resources & $2.73 \mathrm{~mm} \leftrightarrow 2.78 \mathrm{~mm}$ & $<0.0001^{*}$ & $=15.519$ \\
& Revision $\leftrightarrow$ Digital resources & $2.72 \mathrm{~mm} \leftrightarrow 2.78 \mathrm{~mm}$ & $<0.0001^{*}$ & $=23.987$ \\
\hline
\end{tabular}

Table 2. Differences in pupil size

3 An asterisk indicates a significant difference at the Bonferroni-corrected level (see Section 3.3). 
The figures strongly suggest that digital resource consultation is associated with higher cognitive load than translation drafting and revision; in other words, the tasks associated with resource consultation tax more heavily on the cognitive system than the task of translating. The variety of tasks, which was proposed above in relation to the longer fixations, has some merit here also, as attentional switching between activities has been associated with heavier working memory load (Baddeley 2007: 130-132). More specifically, as resource consultation may potentially involve switching between a range of tasks such as image viewing, vertical and horizontal reading and writing, these switches of attention will incur some cost in terms of increased processing load. A related explanation for the relatively smaller pupils during translation has to do with automation. Automation, or automaticity, is the execution of an activity with relatively few cognitive resources (Anderson 2000: 98, Baddeley 2007: 120). In translation, automation has been proposed as a likely explanation for professional translators' relatively smaller pupils compared with those of novice translators (Hvelplund 2016). Through repetition and practice, professional translators have developed habit patterns and schemata which enable them to perform certain tasks, such as typing and text scanning, relatively more effortlessly than novice translators. In the same vein, translators are more likely to develop and apply automated processing for translation drafting and revision than for digital resource consultation, since 'translation proper' constitutes the bulk of the translation time (around 80 per cent, cf. Figure 1, section 4.1. above). In addition, the variety of tasks associated with resource consultation makes automation more difficult and less likely for this complex activity. Nonetheless, automated processes can probably be developed for resource consultation, and comparison of the pupils of professional translators and novice translators would serve as a good testing ground for this intuition.

\subsection{Digital resources in translation}

As noted in the introduction, translators often rely on digital resources such as dictionaries, reference works and parallel texts to solve translation problems and a successful translation will often be the result of the translator's use of digital resources. To date, little research has examined the types of resources that translators use to solve translation problems. This section will consider research question R3:

\section{What types of digital resources are used in translation?}

Section 4.3.1. outlines and examines the kinds of digital resources that have been used in the 18 translators' translations of four different texts. Section 4.3.2. explores individual resource consultation patterns.

\subsubsection{Types of digital resources}

The present study examines the types of digital resources used in 72 translations carried out by 18 professional translators. A variety of digital resources were used to solve a range of problems, most of which were terminological. Table 3 below lists five resource consultation categories, which have been identified in a bottom-up fashion from the translations: bilingual dictionaries, monolingual dictionaries, internet search engines, reference works and websites and conversion tools. ${ }^{4}$ For each category, resources are presented along with the number of consultation events, share of total number of events (in per cent), absolute number and relative percentage of translators using a specific category of resources.

4 Different categorisation may be relevant for other source texts. 


\begin{tabular}{|c|c|c|c|c|}
\hline Type of resource & No. of events & Percentage & Translator\# & Percentage \\
\hline Bilingual dictionaries / term bases & 513 & 75.2 & 17 & 94.4 \\
\hline - $\quad$ Gyldendals Røde Ordbøger & 415 & 60.9 & 15 & 83.3 \\
\hline - $\quad$ Ordbogen.com & 47 & 6.9 & 6 & 33.3 \\
\hline - $\quad$ Regnskabsordbøgerne ${ }^{5}$ & 3 & 0.4 & 1 & 5.6 \\
\hline$-\quad$ IATE $^{6}$ & 48 & 7.0 & 2 & 11.1 \\
\hline Internet search engines & 130 & 19.1 & 12 & 66.7 \\
\hline - Google search & 117 & 17.2 & 12 & 66.7 \\
\hline - $\quad$ Google Images search & 13 & 1.9 & 4 & 22.2 \\
\hline Monolingual dictionaries / term bases & 12 & 1.8 & 3 & 16.7 \\
\hline - $\quad$ Merriam-Webster (EN) & 1 & 0.2 & 1 & 5.6 \\
\hline - $\quad$ Den Danske Ordbog (DA) & 1 & 0.2 & 1 & 5.6 \\
\hline - $\quad$ Retskrivningsordbogen (DA) & 6 & 0.9 & 2 & 11.1 \\
\hline - $\quad$ Synonymordbog.dk (DA) & 4 & 0.6 & 1 & 5.6 \\
\hline Reference works and websites & 19 & 2.8 & 6 & 33.3 \\
\hline - $\quad$ Wikipedia (EN) & 9 & 1.3 & 2 & 11.1 \\
\hline - $\quad$ Wikipedia (DA) & 1 & 0.2 & 1 & 5.6 \\
\hline - $\quad$ arbejdstilsynet.dk & 3 & 0.4 & 1 & 5.6 \\
\hline - $\quad$ bibliotek.dk & 1 & 0.2 & 1 & 5.6 \\
\hline - $\quad$ bog.nu & 1 & 0.2 & 1 & 5.6 \\
\hline - $\quad$ currencies-systems.blogspot.dk & 1 & 0.2 & 1 & 5.6 \\
\hline - $\quad$ danfoss.dk & 1 & 0.2 & 1 & 5.6 \\
\hline - $\quad$ pwc.dk & 2 & 0.3 & 1 & 5.6 \\
\hline Conversion tools & 8 & 1.2 & 5 & 27.8 \\
\hline - $\quad$ Google unit converter & 2 & 0.3 & 2 & 11.1 \\
\hline - $\quad$ metric-conversions.org & 1 & 0.2 & 1 & 5.6 \\
\hline - $\quad$ onlineconversions.com & 2 & 0.3 & 1 & 5.6 \\
\hline - $\quad$ onlineconversions.org & 2 & 0.3 & 2 & 11.1 \\
\hline - Windows calculator & 1 & 0.2 & 1 & 5.6 \\
\hline Total & 682 & - & 18 & - \\
\hline
\end{tabular}

Table 3. Type of resource consultation with numbers of events by type

\section{Bilingual dictionaries}

Bilingual dictionary consultations represent 75 per cent of all digital resource consultations (513 events of 682 events). The general language dictionary Gyldendals Røde Ordbøger is the favoured choice of dictionary with 415 search events while the general language dictionary Ordbogen.com accounts for 47 search events. Based on these figures, it seems that there is heavy reliance on general language dictionaries to solve a variety of translation problems. The specialised language dictionaries Regnskabsordbøgerne.com and IATE account for 51 search events. Interestingly, while 15 translators use general language dictionaries, only three translators use specialised language dictionaries. It would have seemed likely that more translators had opted for specialised dictionaries, especially in the translation of the two LSP texts. Those two texts contain specialised terms that are often not included in the general language dictionaries. However, only three dif-

5 English-Danish and Danish-English accounting dictionaries (https://www.ordbogen.com).

6 InterActive Terminology for Europe, The EU's multilingual term base (http://iate.europa.eu) 
ferent translators used the specialised dictionaries Regnskabsordbøgerne (accounting dictionary) and IATE (multilingual term base). Thus it seems, based on these 72 translations, that the use of specialised language dictionaries is not as common as it might be assumed.

\section{Internet search engines}

Google search is a popular digital resource, which is used by 12 of the study's 18 translators. A total of 117 Google search events are performed, constituting little more than 17 per cent out of a total of 682 resource consultation events. Three broad categories of Google queries can be surmised from the data: navigational queries, deep queries and shallow queries. The purpose of a navigational query is to reach a particular website via Google's search engine by typing the website's name in Google search. The purpose of deep queries is to find relevant information in relevant websites using e.g. Google's search engine as a facilitator. Relevant key terms are queried in Google search, and the search engine then returns relevant websites for the user to navigate to. The purpose of shallow queries is also informational, but the translator will remain in the website space of Google's search engine. Inside this website space, the translator may browse text snippets or check an expression's context and frequency, often by restricting a search query with inverted commas. Shallow queries are by far the most common type of query comprising no less than 91 per cent (106 queries) of the total number of queries. Deep queries comprise 4 per cent ( 5 queries) of the total while navigational queries make up around 5 per cent (6 queries) of all Google searches. Interestingly, only Google Search was used by the translators. No other search engines, including Microsoft Bing, were used.

Google Images search is used in the translation of both literary and LSP texts, presumably to identify the meaning of a ST item and to pair a potential TT equivalent with the ST item. This form of aid in the comprehension and reformulation processes is an interesting alternative search strategy, which may, in some cases, complement (or even replace) 'traditional' text-based search strategies. For instance, in one instance, an image search for the term "pill caddy" (Text 2) is followed by an image search for the Danish equivalent "pilleæske", which confirmed this would be an adequate translation for the term. Interestingly, only four translators opt for this strategy of image search. The use of this strategy is probably highly sensitive to translator preference and text type, but the strikingly low number of search events (around 2 per cent, namely 13 out of 682 events) indicates that there is further potential for image-based search strategies. In a wider pedagogical context, image search might be included more systematically in teaching as a key problem-solving strategy.

\section{Monolingual dictionaries}

Three translators use four different monolingual dictionaries and perform a total of 12 consultations. The American English dictionary and thesaurus Merriam-Webster is used in one case to look up the word "translational" (Text 3). Den Danske Ordbog (general dictionary), Retskrivningsordbogen (spelling dictionary) and Synonymordbog.dk (thesaurus) were used especially to solve spelling problems and to find synonyms. Overall, monolingual dictionaries were rarely used to solve spelling problems and it is clear that the spell checking system built into the text processor Microsoft Word is the translator's most important tool with respect to verifying spelling (and grammar).

\section{Reference works and websites}

A third of the translators use some kind of informational website to aid in the solution of specific translation problems. Wikipedia encyclopaedia (English and Danish versions) is used by three translators, for instance to look up the chemical compound He (Text 4) and to read about the author Douglas Coupland (Text 2). Websites containing texts on specific text-related topics are used to examine the meaning of specialised terminology: the Danish website of the international ac- 
counting company PricewaterhouseCoopers (www.pwc.dk) is used to examine the term "GAAP" while the website of the Danish Working Environment Authority (Arbejdstilsynet, www.arbejdstilsynet.dk) is used to study general terminology in relation to Text 4.

A total of 19 consultations were made within this category, which corresponds to less than three per cent of all consultations. Considering the LSP characteristics of Texts 3 and 4, an extract from an annual report from the British American Tobacco Company and an extract from a technical report, respectively, this figure is surprisingly low. Both texts are dense with low-frequent specialised terminology, which is not typically found in general language dictionaries, and it would seem likely that translators would make frequent use of websites that contain accounting and technical texts. However, only four such websites are used by four different translators on a few occasions. This surprising behaviour may be because the translators are able to translate without external help since they know the translation equivalent already. This is not very likely, though, since the texts are very different and highly specialised within their own terminological areas, and in addition, nine translators specialise in literary translation and would rarely encounter these types of text. Instead, it might be that translators solve terminological issues with a specialised bilingual dictionary, but as noted above, specialised dictionaries are also rarely used. The limited use of specialist websites and specialised dictionaries thus strongly indicate that translators will often make a guess for a low-frequent 'difficult' term, possibly because they do not have a set of strategies available to identify a likely translation equivalent. This can become problematic as regards the quality of the target text. In a pedagogical context, the role of using parallel texts from domain relevant websites might be emphasised (more).

\section{Conversion tools}

Five translators use five different conversion and calculation tools, including the Windows Calculator and websites dedicated to e.g. metric conversion. An example of a translation problem where conversion tools are used is "six-foot-something" from Text 1 , which is converted into metres. Another example is from Text 4 , in which " 200 degrees F" is converted into degrees Celsius. The use of conversion tools is closely related to the nature of the text and to the problems it poses and is not expected to occur in most other texts, but the use of specific conversion tools indicate an awareness and readiness to apply a specific set of problem solving strategies to solve quite specific problems.

\subsubsection{Individual patterns}

The investigations above have aimed at uncovering overall patterns in translators' use of digital resources based on a population of 18 translators. However, no two translators are alike and there is surely variation in the use of digital resources from one translator to the other. This section will explore different kinds of digital resource consultation behaviour. Table 4 below outlines the use of digital resources by the 18 translators in the study. The six categories of resources are bilingual dictionaries, monolingual dictionaries, Google search, Google Images search, external reference and/or website and, finally, the category other. 


\begin{tabular}{|c|c|c|c|c|c|c|c|}
\hline & Bilingual & Monolingual & Google search & Google Images & $\begin{array}{l}\text { Reference / } \\
\text { website }\end{array}$ & Other & Total \\
\hline P1 & $\mathrm{x}$ & - & $\mathrm{x}$ & $\mathrm{x}$ & $\mathrm{x}$ & - & 4 \\
\hline $\mathbf{P 2}$ & $\mathrm{x}$ & - & $\mathrm{x}$ & - & $\mathrm{x}$ & - & 3 \\
\hline P3 & $\mathrm{x}$ & - & $\mathrm{x}$ & - & - & - & 2 \\
\hline P4 & $\mathrm{x}$ & - & $\mathrm{x}$ & $\mathrm{x}$ & $\mathrm{x}$ & $\mathrm{x}$ & 5 \\
\hline P5 & $\mathrm{x}$ & - & $\mathrm{x}$ & - & - & - & 2 \\
\hline P6 & $\mathrm{x}$ & - & $\mathrm{x}$ & - & $\mathrm{x}$ & - & 3 \\
\hline P7 & $\mathrm{x}$ & - & - & - & - & - & 1 \\
\hline P8 & $\mathrm{x}$ & $\mathrm{x}$ & $\mathrm{x}$ & - & $\mathrm{x}$ & $\mathrm{x}$ & 5 \\
\hline P9 & $\mathrm{x}$ & - & $\mathrm{x}$ & $\mathrm{x}$ & - & $\mathrm{x}$ & 4 \\
\hline P10 & $\mathrm{x}$ & - & - & - & - & - & 1 \\
\hline P11 & $\mathrm{x}$ & - & - & - & - & - & 1 \\
\hline P12 & $\mathrm{x}$ & $\mathrm{x}$ & $\mathrm{x}$ & $\mathrm{x}$ & - & $\mathrm{x}$ & 5 \\
\hline P13 & $\mathrm{x}$ & - & $\mathrm{x}$ & - & - & $\mathrm{x}$ & 3 \\
\hline P14 & $\mathrm{x}$ & $\mathrm{x}$ & $\mathrm{x}$ & - & - & - & 3 \\
\hline P15 & $\mathrm{x}$ & - & - & - & - & - & 1 \\
\hline P16 & $\mathrm{x}$ & - & - & - & - & - & 1 \\
\hline P17 & $\mathrm{x}$ & - & - & - & - & - & 1 \\
\hline P18 & - & - & $\mathrm{x}$ & - & $\mathrm{x}$ & - & 2 \\
\hline Total & 17 & 3 & 12 & 4 & 6 & 5 & - \\
\hline
\end{tabular}

Table 4. Type of resource consultation by translator

Almost all translators use a bilingual dictionary at one point during the translation process. Only one translator did not use any bilingual dictionary, but interestingly that translator used Google Search and the Wikipedia encyclopaedia. The second most popular type of resource is Google search, which is used by roughly 67 per cent of the translators. The broad category of reference works and websites, comprising the Wikipedia encyclopaedia and specialist websites with relevant parallel texts, is the third most popular category and is used by roughly 33 per cent of the translators. Five translators ( 28 per cent) use some type of conversion tool, four translators (22 per cent) use Google's image search while three translators (17 per cent) use a monolingual dictionary.

While it might be tempting to assume that the solution of specific translation problems demands specific translation tools and strategies, the figures above indicate the contrary: translators seek different solutions to the same translation problems. In Text 4, for instance, six translators resorted to three different digital resources to translate the term "funneled tubing": one translator (P1) used Google search, presumably to skim the results to see the term in different contexts. Three translators (P2, P6, P15) used the bilingual dictionary Gyldendals Røde Ordbøger to find a Danish equivalent, while two translators (P4, P12) used Google's image search to find images of the item they were translating. All translation solutions are considered to be acceptable, and the variation shows that different translation strategies are used for the same translation problem.

It is clear from the figures above that translators use digital resources quite differently. While the average number of different resources used by the translators is 2.6 , six translators use just one kind of resource while three translators use five different kinds of resources. The number of different types of digital resources used by a translator may be an indicator of their search profile. Three levels of categorisation into search profiles is proposed here: translators who use 1-2 different types of digital resources have a relatively simpler search profile, those who use 3-4 different types of resources have a moderately advanced search profile while those who use 5-6 different types of resources have an advanced search profile. Future studies may examine if such search 
profiling is meaningful in relation to other types of translator behaviour profiling (e.g. Dragsted/ Carl 2013).

\section{Summary and concluding remarks}

The focus of this paper has been to investigate translators' use of digital resources during translation. One central question was to examine the importance of digital resource consultation in relation to the overall translation process. The findings show that digital resource consultation constitutes a considerable amount of the overall translation task time, namely nearly 20 per cent (around 25 per cent for LSP texts and 11 per cent for literary texts). This finding is remarkable as it suggests that the role and use of resources needs to be given more attention in process research at large. Examining translators' use of resources as a substantial part of the translation process research will permit studies to assume a higher level of completeness in the description of the translation process.

The study also examined if and to what extent reading behaviour and cognitive load are different during resource consultation than during translation drafting and revision. Fixation durations were found to be significantly longer and pupils to be significantly larger for resource consultation, indicating heavier processing and higher cognitive load for this complementary translation activity. As regards the study's third research question, it was observed that the translators used a variety of different tools and different problem solving strategies to solve the same translation problems. However, bilingual dictionaries were found to be the far most popular digital resource.

This study has demonstrated that digital resource consultation constitutes an important part of the translation process and that it could play a more important role in translation process research. Future studies may explore the process-product paradigm and examine how search patterns and search profiles may be linked with the translation product. In addition, studies may examine other aspects of translators' use of digital resources, including differences between professional translators and novices, differences in eye movements and cognitive load for different types of digital resources, if some resources are better than others to solve certain kinds of problems etc. In addition, an interesting practical application of this research is in translation teaching. The findings may be converted into practical guidelines that can help translators use digital resources in a better and more practical way. While this study has applied mainly eye tracking data, it could yield interesting results to combine this quantitative approach with a more qualitative one, including e.g. questionnaire data, interview data. Such data would provide more detailed information about translators' preferences and familiarity with different tools - not least those tools that were not used by the translators.

\section{References}

Anderson, John R. 2000: Cognitive Psychology and its Implications (5th ed.). New York: Worth.

Baayen, Rolf Harald 2009: Analyzing Linguistic Data: A Practical Introduction to Statistics Using R (3rd ed.). Cambridge: Cambridge University Press.

Baddeley, Alan D. 2007: Working Memory, Thought and Action. Oxford: Oxford University Press.

Balling, Laura Winther 2008: A brief introduction to regression designs and mixed-effects modelling by a recent convert. In Göpferich, Susanne/Jakobsen, Arnt Lykke/Mees, Inger M. (eds.), Looking at Eyes. Eye-Tracking Studies of Reading and Translation Processing. Copenhagen: Samfundslitteratur, 175-192.

Balling, Laura Winther/Hvelplund, Kristian Tangsgaard 2015: Design and Statistics in Quantitative Translation (Process) Research. In Alves, Fabio/Hurtado, Amparo/Lacruz, Isabel/Muñoz Martín, Ricardo (eds.), Translation as a cognitive activity (Translation Spaces). Amsterdam and Philadelphia: John Benjamins, 170-187.

Carl, Michael 2012: Translog-II: a program for recording user activity data for empirical reading and writing research. In Proceedings of the Eight International Conference on Language Resources and Evaluation, European Language Resources Association, Istanbul, Turkey. May 2012, 4108-4112.

Dragsted, Barbara/Carl, Michael 2013: Towards a classification of translation styles based on eye-tracking and keylogging data. In Journal of Writing Research 5 (1), 133-158. 
Hess, Eckhard H./Polt, James M. 1964: Pupil size in relation to mental activity in simple problem solving. In Science $143,1190-1192$.

Hvelplund, Kristian Tangsgaard 2011: Allocation of Cognitive Resources in Translation: An eye-tracking and Key-logging Study. PhD thesis. Copenhagen: Copenhagen Business School.

Hvelplund, Kristian Tangsgaard 2016: Cognitive efficiency in translation. In Muñoz Martín, Ricardo (ed.), Reembedding Translation Process Research. Amsterdam and Philadelphia: John Benjamins.

Hvelplund, Kristian Tangsgaard 2017: Four fundamental types of reading during translation. In Jakobsen, Arnt Lykke/ Mesa-Lao, Bartolomé (eds.), Translation in Transition.

Hvelplund, Kristian Tangsgaard/Dragsted, Barbara 2017: Genre familiarity and translation processing: differences and similarities between literary and LSP translators. In Lacruz, Isabel/Jääskeläinen, Riitta (eds.), Innovation and Expansion in Translation Process Research.

Jakobsen, Arnt Lykke 2002: Translation drafting by professional translators and by translation students. In Trigo, Elena Sánchez/Fouces Óscar, Diaz (eds.), Traducción \& Comunicación 3. Vigo: Universidade de Vigo, 89-103.

Jakobsen, Arnt Lykke/Jensen, Kristian Tangsgaard Hvelplund 2008: Eye Movement Behaviour across Four Different Types of Reading Task. In Göpferich, Susanne/Jakobsen, Arnt Lykke/Mees, Inger M. (eds.), Looking at Eyes: Eye-tracking Studies of Reading and Translation Processing. Copenhagen: Samfundslitteratur, 103-124.

Jakobsen, Arnt Lykke/Schou, Lasse 1999: Translog Documentation Version 1.0. In Hansen, Gyde (ed.), Probing the Process of Translation: Methods and Results Appendix 1 (Copenhagen Studies in Language 24). Copenhagen: Samfundslitteratur, 1-36.

Just, Marcel A./Carpenter, Patricia A. 1980: A Theory of Reading: From eye fixations to comprehension. In Psychological Review 87(4), 329-354.

Rayner, Keith 1998: Eye movements in reading and information processing: 20 years of research. In Psychological Bulletin 124 (3), 372-422.

Rele, Rachana S./Duchowski, Andrew T. 2005: Using Eye Tracking to Evaluate Alternative Search Results Interfaces. In Proceedings of the Human Factors and Ergonomics Society Annual Meeting 49, 1459-1463.

Simonsen, Henrik Køhler 2009: Se - og du skal finde: en eyetrack-undersøgelse med særlig fokus på de leksikografiske funktioner. In Nordiske studier i leksikografi 11. Rapport fra Konference om leksikografi i Norden. Finland 3-5 June 2009. Tampere: Nordisk forening for leksikografi 2009, 274-288.

Simonsen, Henrik Køhler 2011: User Consultation Behaviour in Internet Dictionaries: An Eye-Tracking Study. In Hermes 46, 75-101. 


\section{Appendix 1}

Text 1 (954 characters)

John Le Carré: Single \& Single

And his binges - three there'd been till now - so controlled they scared the wits out of her. Oh, she'd had lodgers who took a drop. Shared a drop with them sometimes, to be friendly, keep an eye. But never before had a taxi pulled up at daybreak, twenty yards down the road so as not to wake anyone, and delivered a deathly pale, mummified six-foot-something hulk who had to be nursed up the steps like a bomb casualty, with his overcoat hung round him and his beret straight as a ruler across his forehead - yet was still able to fish out his wallet, select a twenty for the driver, whisper, "Sorry, Elsie," and with only a little help from her, haul himself upstairs without disturbing a soul except Sammy, who had waited all night for him. Through the morning and afternoon, Oliver had slept, which is to say Elsie heard no creak or footfall through the ceiling, and listened in vain for the knocking of the water pipes.

\section{Text 2 (1030 characters)}

Douglas Coupland: All Families are Psychotic

She looked at the motel's bed side clock: 7:03 A.M. Pillo'clock. She took two capsules from her prescription pill caddie and swallowed them with tap water gone flat overnight, which now tasted like nickels and pennies. It registered on her that motel rooms now came equipped with coffee makers. What a sensible idea, so bloody sensible - why didn't they do this years ago? Why is all the good stuff happening now? A few days back, on the phone, her daughter, Sarah, had said, 'Mom, at least buy Evian, OK? The tap water in that heap is probably laced with crack. I can't believe you chose to stay there.'

'But dear, I don't mind it here.' 'Go stay at the Peabody with the rest of the family. I've told you a hundred times I'll pay.'

'That's not the point, dear. A hotel really ought not cost more than this.'

'Mom, NASA cuts deals with the hotels, and ...' Sarah made a puff of air, acknowledging defeat. 'Forget it. But I think you're too well off to be pulling your Third World routine.

\section{Text 3 (1088 characters)}

The results of the Group were impacted by the adverse movement of a number of key currencies and this is reflected in an adverse translational exchange rate movement of around $4 \%$. As a result, reported revenue was slightly up to $£ 315,260$ million and profit from operations was higher by $3 \%$ to $£ 35,526$ million. To better understand the underlying performance of the business, management reviews the results by adjusting for a number of items relating to significant restructuring and integration costs and one-off charges, provisions and income. We call the underlying profit after adjusting for these items, which are described further below, adjusted profit from operations. Adjusted profit from operations was $£ 35,820$ million, up 3\% from $£ 35,641$ million in 2012. In order to assess the underlying performance, we also have to view the business results at constant rates of exchange, excluding the translational impact of exchange rate movements. This does not adjust for the transactional effects of currency fluctuations. The above non-GAAP measures are explained later in this review. 
Text 4 (789 characters)

2.4: LEAK TEST (HIGH TEMPERATURE)

Purpose: Each test sample was tested at max service pressure at the high temperature of 200 degrees F. The procedures for leakage testing are outlined below. The test samples were tested individually.

Test Procedure: Chamber was conditioned to high component service temperature of 200 degrees F for 2 hours with immersion fluid compatible with the extreme temperature. Both inlet and outlet of components were capped and were conditioned at temperature for 2 hours. After conditioning, the inlet cap was removed and pressurized with He to maximum service pressure. The test samples were immersed in fluid and observed for leaks for 5 minutes. If any leaks appear, route funneled tubing to graduated cylinder for leaks measurement. Leaks are not allowed 